\title{
EL CENTRO-SUDOESTE DE LA PROVINCIA DEL CHACO (ARGENTINA): UN BASTIÓN AGRÍCOLA
}

\section{THE CENTER-SOUTHWEST OF THE PROVINCE OF CHACO (ARGENTINA): AN AGRICULTURAL BASTION}

\author{
Dante Edin Cuadra \\ Nelson Adrián Mónaca \\ Universidad Nacional del Nordeste. Facultad de Humanidades. Dpto. de Geografía. \\ dantecuadra@yahoo.com
}

\section{Resumen}

En función de las cotizaciones globales de algunos commodities, la provincia del Chaco dejó de ser una provincia predominantemente algodonera para convertirse en productora de soja. La siembra de esta oleaginosa adquirió cierta importancia en la década de 1990, pero fue a partir de los primeros años del siglo XXI cuando logró establecerse fuertemente en este espacio.

Las transformaciones productivas operadas en el Chaco no sólo son generadoras de cambios fisonómicos o paisajísticos, sino que conllevan múltiples implicaciones a nivel tecnológico, empresarial, económico, sociodemográfico, cultural y ambiental.

El Centro-Sudoeste se ha consolidado como el área núcleo de la producción agrícola del Chaco, donde se asienta el $70 \%$ de la superficie sojera de la provincia, el $80 \%$ de las tierras dedicadas al algodón, girasol, sorgo y trigo y, aproximadamente, el 70\% del área sembrada con maíz.

En contraposición, la mitad oriental del Chaco ha perdido toda trascendencia agrícola en los últimos años, perfilándose como un territorio de ganadería bovina extensiva. Paralelamente, el territorio Noroccidental de la provincia experimenta un proceso de desmonte e implantación de actividades agropecuarias, pero todavía en una escala de producción de menor magnitud.

\begin{abstract}
As a result of the global prices of some commodities, the province of Chaco went on to produce more soybeans than cotton. Soybean planting acquired some importance in the 1990s, but it was in the early years of this century when it managed to establish itself strongly in this area.

Productive transformations in the Chaco are not only generating physiognomic or landscape changes, but they carry many implications at a technological, business, economic, socio-demographic, cultural and environmental level.

The Center-Southwest has become the core area of agricultural production in the Chaco, comprising $70 \%$ of the soybean area of the province, $80 \%$ of the land dedicated to cotton, sunflower, sorghum and wheat and, approximately, $70 \%$ of the area sown with maize.

In contrast, the eastern half of Chaco has lost all agricultural importance in recent years, emerging as an area of extensive cattle ranching. In parallel, the Northwest territory of the province undergoes a process of deforestation and implementation of agricultural activities but still on a production scale of lesser magnitude.
\end{abstract}

\section{Palabras claves}

Chaco; Agricultura; Algodón; Soja; Girasol; Maíz; Sorgo; Trigo.

\section{Keywords}

Chaco; Agriculture; Cotton; Soybeans; Sunflower; Maize; Sorghum; Wheat. 
Revista Geográfica Digital. IGUNNE. Facultad de Humanidades. UNNE. Año 13. № 26. Julio - Diciembre 2016. ISSN 1668-5180 Resistencia, Chaco

\section{Objetivos}

* Reconocer la importancia adquirida por la producción agrícola en la región Centro-Sudoeste del Chaco, entre 1980 y 2015.

* Mostrar las transformaciones productivas operadas en este territorio a lo largo del período considerado.

* Reflexionar sobre las implicaciones sociales y ambientales que involucran dichos cambios en el espacio geográfico.

\section{Introducción}

El espacio Centro-Sudoccidental chaqueño es conocido como la Planicie Centrochaqueña, en gran medida arreica, donde predominan las deposiciones eólicas, suelos excepcionalmente anegables y no anegables, correspondientes climáticamente al Chaco Central Semiárido. La altimetría es ascendente de SE a NO desde 70 a $150 \mathrm{~m} / \mathrm{s} / \mathrm{n} / \mathrm{m}$ y, en las formaciones boscosas allí existentes, conviven los quebrachos colorados chaqueño y santiagueño. (Bruniard, E., 1979)

Este territorio se abrió a la colonización agrícola a partir de la segunda década del siglo XX, especialmente con la incorporación de colonos inmigrantes eslavos y germanos, quienes llegaron a esas tierras en el período de entre-guerras, a los que se sumaron pobladores de distintos orígenes.

Entre 1930 y 1960 se constituyó en un área de gran importancia en la producción algodonera, albergando verdaderas cuencas productivas con nodos en Presidencia Roque Sáenz Peña, Las Breñas-Charata y Villa Ángela. En el último cuarto del siglo XX este espacio sufrió una fuerte depredación de sus bosques nativos con la finalidad de extender la frontera agropecuaria.

Tras la crisis algodonera, luego de 1960, el área fue escenario, en gran medida, del proceso de "pampeanización" que se desarrolló en el Chaco (propagación de los cultivos de girasol, maíz, sorgo y trigo) en función de contar con explotaciones más amplias que las chacras algodoneras minifundistas que caracterizaban al Centro-Este de la provincia. Dichos cultivos, para ser rentables, requerían tierras de mayores superficies y laboreo mecanizado.

El presente trabajo toma en consideración el proceso desencadenado posteriormente, es decir, desde 1980 en adelante, con la finalidad de poner en evidencia el gran dinamismo que tomó la agricultura en esta región en el transcurso de las últimas décadas.

\section{Desarrollo}

\section{Regiones productivas}

Considerando la matriz productiva primaria que se ha configurado en la provincia del Chaco en los últimos treinta años, se pueden reconocer tres grandes unidades geográficas, que son: el Chaco Centro-Oriental (región con un perfil netamente ganadero bovino extensivo), el Chaco Noroccidental (territorio forestal e incipientemente agropecuario) $\mathrm{y}$, finalmente, el espacio que nos interesa desarrollar en este artículo, el Chaco Centro-Sudoccidental (ámbito de fuerte desarrollo agrícola).

El Centro-Sudoeste del Chaco involucra diez departamentos que contienen núcleos urbanos de gran importancia en la provisión de servicios de este territorio: Comandante Fernández (Presidencia Roque Sáenz Peña), Independencia (Campo Largo, Avia Terai y Napenay), General Belgrano (Corzuela), 9 de Julio (Las Breñas), Chacabuco (Charata), 12 de Octubre (General Pinedo, Gancedo y General Capdevila)), 2 de Abril (Hermoso Campo), O`Higgins (San Bernardo, La Clotilde y La Tigra), Mayor Luis Fontana (Villa Ángela, Coronel Du Graty y Enrique Urien) y Fray Justo Santa María de Oro (Santa Sylvina) en un área de $19.727 \mathrm{~km}^{2}$, equivalente al $20 \%$ del territorio chaqueño.

Este espacio geográfico, si bien ha consolidado un status agrícola de primera jerarquía a nivel provincial, aún tiene a la ganadería, sobre todo bovina y, en menor medida caprina y porcina, como una actividad de segundo orden y con tendencia decreciente en los últimos años, especialmente en las existencias de ganado mayor. No obstante, el sur de la región (oeste y sur del departamento Fray Justo Santa María de Oro y, además, el sur y sudeste de Mayor Luis Fontana) se caracteriza por

Publicado en formato digital: Dr. Dante Edin Cuadra y Sr. Nelson Adrián Mónaca. EL CENTRO-SUDOESTE DE LA PROVINCIA DEL CHACO (ARGENTINA): UN BASTIÓN AGRÍCOLA. Revista Geográfica Digital. IGUNNE. Facultad de Humanidades. UNNE. Año 13. N N 26. Julio - Diciembre 2016. ISSN 1668-5180 Resistencia, Chaco.

En: http://hum.unne.edu.ar/revistas/geoweb/default.htm 
presentar ambientes con caracteres ecológicos de menor aptitud para el desarrollo de cultivos y, por tanto, esas tierras se destinan a la producción ganadera bovina de carácter extensivo, sobre campos de gran extensión situados sobre suelos pobres, salinos o inundables que se vinculan o forman parte de los Bajos Submeridionales.

Otra particularidad de este espacio es el contacto fluido y cotidiano que tiene con las provincias vecinas, particularmente con el oriente de Santiago del Estero y el norte de Santa Fe. Allí, los límites interprovinciales no representan barrera alguna desde el punto de vista natural, demográfico, social y productivo, existiendo lazos parentales, laborales, societarios y económicos que integran a las jurisdicciones y generan un tejido social caracterizado por cadenas de relaciones que le otorgan identidad como territorio.

Por cierto, la propagación de la soja (planta perteneciente a la familia de las leguminosas o fabáceas) en el área fue un factor generador de cambios, entre los que podemos citar: afluencia de nuevos productores, contratistas y empresarios, muchos de ellos provenientes de Córdoba, Santa Fe y Buenos Aires, instalación de agro-empresas, arribo de maquinarias y tecnologías, mayor demanda de técnicos y profesionales vinculados con los servicios agrícolas y una gran dinámica en el sector transportista. Con ello, también aparecieron nuevas dificultades, tales como los problemas ambientales y de la salud ante el uso generalizado de agro-tóxicos, la emigración de pequeños productores y la simplificación de los ecosistemas.

Figura $N^{\circ}$ 1:

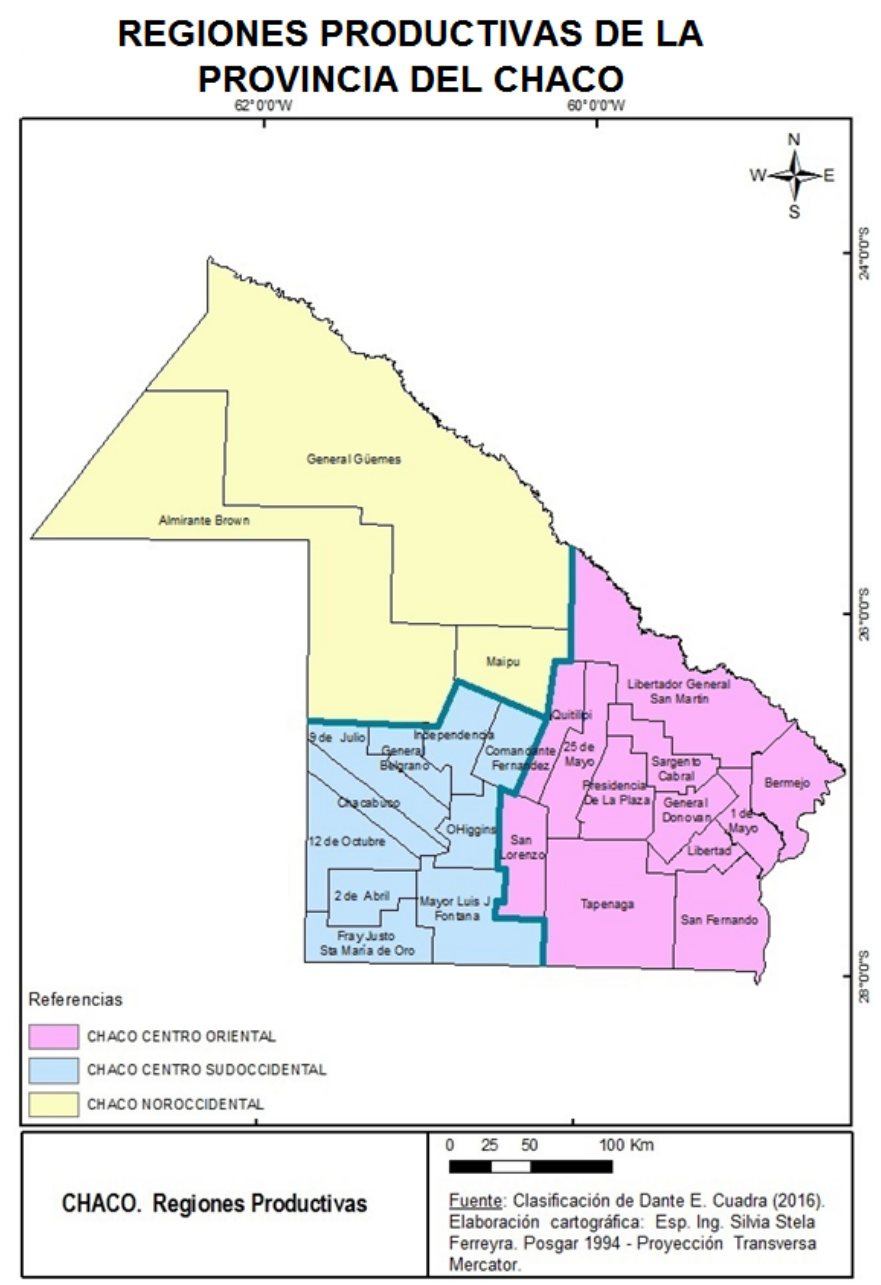

Publicado en formato digital: Dr. Dante Edin Cuadra y Sr. Nelson Adrián Mónaca. EL CENTRO-SUDOESTE DE LA PROVINCIA DEL CHACO (ARGENTINA): UN BASTIÓN AGRÍCOLA. Revista Geográfica Digital. IGUNNE. Facultad de Humanidades. UNNE. Año 13. No 26. Julio - Diciembre 2016. ISSN 1668-5180 Resistencia, Chaco.

En: http://hum.unne.edu.ar/revistas/geoweb/default.htm 


\section{Superficie cultivada por regiones productivas en el Chaco}

Durante los años ' 80 y principios de los '90, las tierras cultivables en la provincia apenas lograban superar las 700.000 hectáreas en algunas campañas, pero desde mediados de la década de 1990 hasta el año 2007 se anexaron un millón de hectáreas con fines agrícolas, la mayor parte de ellas localizadas en la región Centro-Sudoeste. Este territorio, junto a su contiguo del Este de la provincia de Santiago del Estero, sufrió un vigoroso proceso de deforestación en esos años, que posibilitó sembrar algodón (planta de la familia de las Malváceas) en forma mecanizada, alcanzándose cifras records de producción en el Chaco en la década de 1990. Con la nueva crisis algodonera (1998/99), los altos precios internacionales alcanzados por la soja y la fuerte demanda de China, esas tierras se reorientaron rápidamente hacia el cultivo de la oleaginosa.

Hasta el año 2009, la región Centro-Oriental ocupó el segundo lugar en superficie agrícola, pero este espacio -que nunca encontró alternativas viables dentro de la agricultura, tras la crisis algodoneraredujo fuertemente el área sembrada después de 2011. En los últimos años, el área Noroccidental amplió visiblemente las tierras destinadas a sembradíos, merced al desmonte, alcanzando el segundo lugar en extensión de tierras cultivadas.

En cuanto al Centro-Sudoeste del Chaco, desde el último cuarto del siglo XX ha sido objeto de la tala forestal, con la finalidad de ampliar la actividad agropecuaria, situación que se potenció a partir de la década de 1990 cuando llegó a superar las 700.000 hectáreas de siembra. En los últimos años la ganadería ha perdido terreno con respecto a la agricultura en este espacio; esta última, en algunas campañas ha logrado sobrepasar el millón de hectáreas cultivadas, aunque desde 2007 en adelante no ha mostrado incrementos llamativos en esta materia.

Figura $\mathbf{N}^{\circ}$ 2:

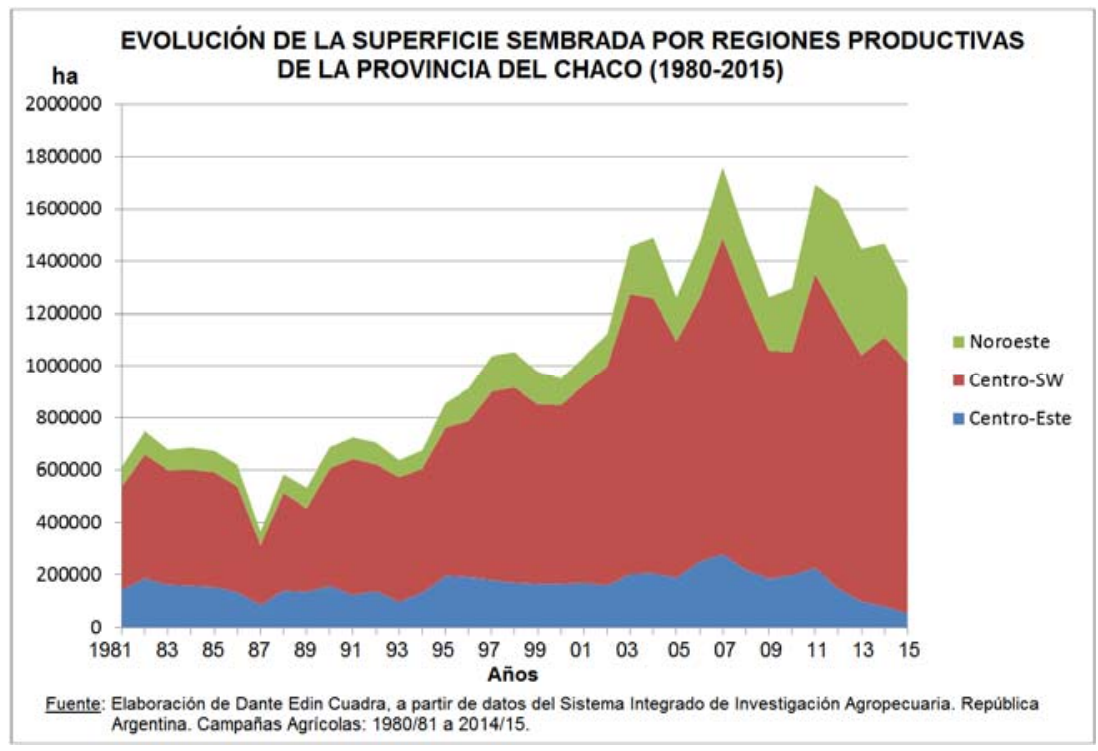

En términos relativos, puede verse la participación decreciente de la región Centro-Este en la superficie destinada a siembra a lo largo del período considerado, pasando de $25 \%$ en los años ' 80 a sólo $5 \%$ a mediados de la década de 2010.

El Centro-Sudoeste presenta valores que oscilan entre el 65 y el $75 \%$ de las tierras cultivadas en el Chaco en el mismo tramo temporal, lo que permite dimensionar la fuerte gravitación que posee esta región a escala provincial.

El sector Noroccidental ha participado, durante gran parte del período, con valores cercanos al $15 \%$, pero en los últimos años contribuye con una proporción más elevada, del orden del $25 \%$. Esta región, en los últimos años, provee las $2 / 3$ partes de las maderas extraídas de los bosques nativos del Chaco,

Publicado en formato digital: Dr. Dante Edin Cuadra y Sr. Nelson Adrián Mónaca. EL CENTRO-SUDOESTE DE LA PROVINCIA DEL CHACO (ARGENTINA): UN BASTIÓN AGRÍCOLA. Revista Geográfica Digital. IGUNNE. Facultad de Humanidades. UNNE. Año 13. № 26. Julio - Diciembre 2016. ISSN 1668-5180 Resistencia, Chaco.

En: http://hum.unne.edu.ar/revistas/geoweb/default.htm 
por lo que la relación es directa entre la deforestación y el uso inmediato de las tierras en la actividad agropecuaria. Un proceso semejante, pero más impulsivo, se vio en el Sudoeste de la provincia en los años '70 y en las décadas siguientes, que se prolongó en el primer decenio del presente siglo, cuando la presión por ampliar la frontera agrícola arremetió contundentemente contra los bosques nativos.

Svampa, refiriéndose al ingreso de los commodities a América Latina, afirma que se trata de "...un nuevo orden económico y político-ideológico, sostenido por el boom internacional de los precios de la materia prima y los bienes de consumo demandados cada vez más por los países centrales y las potencias emergentes. Este orden va consolidando un estilo de desarrollo neoextractivista que genera ventajas comparativas, visibles en el crecimiento económico, al tiempo que produce nuevas asimetrías y conflictos sociales, económicos, ambientales y político-culturales". (Svampa, M., 2013)

Figura $\mathbf{N}^{\circ}$ 3:

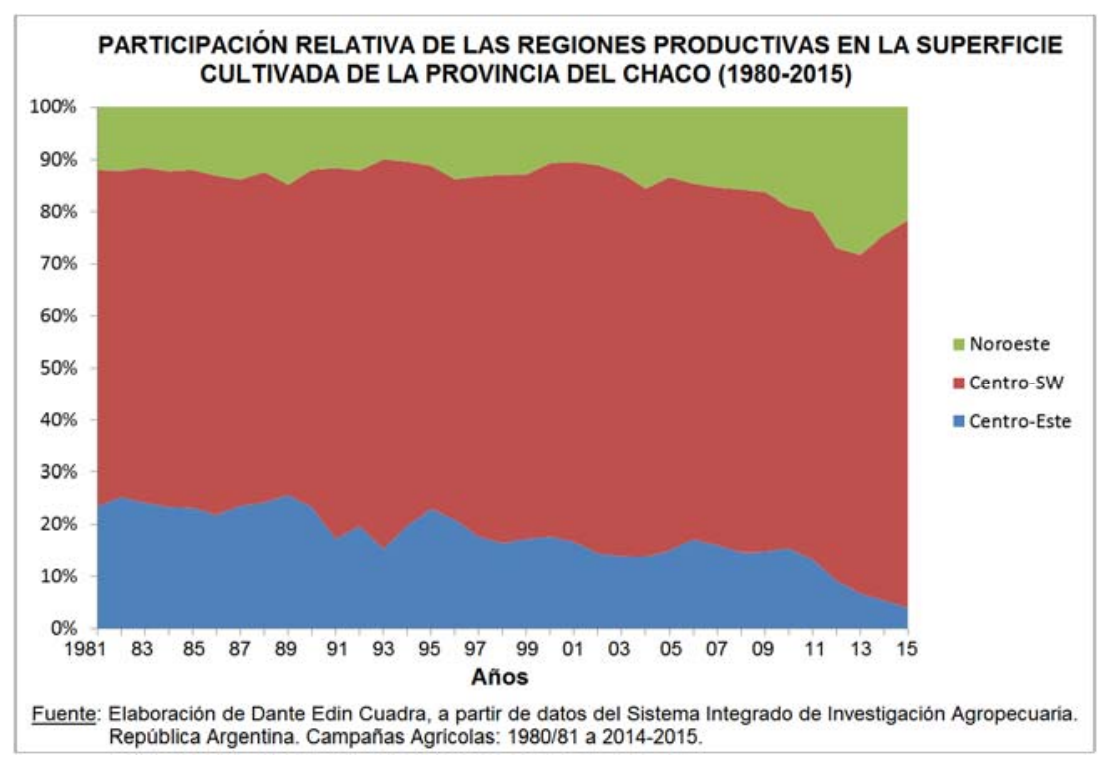

\section{Los cultivos que prevalecen en el Centro-Sudoeste del Chaco}

Entre 1980 y fines de la década de 1990 el algodón fue el cultivo predilecto, en líneas generales, por los productores de esta región, con los típicos altibajos en la cobertura sembrada entre una campaña y otra, cuyas causales deben buscarse en la dinámica meteorológica, el nivel de precios de la fibra en el mercado y las medidas políticas de promoción capaces de alentar esperanzas a la hora de iniciar la siembra. En los años '80, el sorgo y el girasol llegaban a disputarle la preeminencia al cultivo textil en algunas campañas, situación que no se dio en la década siguiente ante la gran recuperación que mostró la actividad algodonera. Al respecto, el Prof. Manoiloff ha reconocido que "La crisis del algodón hizo que se buscaran alternativas válidas para superarla. Las más eficaces vinieron del lado del Instituto Nacional de Tecnología Agropecuaria, decidido a crear nuevas variedades que se tradujeron en más cantidad y mejor calidad adaptadas a las condiciones medioambientales de la región algodonera y a las nuevas exigencias de la industria textil". "El éxito de las nuevas variedades logradas se hizo notar particularmente en las décadas de 1980 y 1990 con rendimientos que duplicaron los obtenidos de 1970 hacia atrás". Asimismo, "La política económica jugó su parte. Las sucesivas devaluaciones tuvieron algún efecto positivo cuando estimulaban la exportación, pero las mismas, fueron negativas a la hora de importar insumos necesarios inexistentes en el país". (Manoiloff, R., 2001)

En los años finales de los '90 y primeros del siglo XXI, la soja dio el gran salto cuantitativo en esta parte del Chaco, pasando de 100.000 a poco menos de 600.000 hectáreas, en tanto el girasol, el maíz y el trigo lograban superficies de siembra que dejaban en situación de postergación al algodón.

Publicado en formato digital: Dr. Dante Edin Cuadra y Sr. Nelson Adrián Mónaca. EL CENTRO-SUDOESTE DE LA PROVINCIA DEL CHACO (ARGENTINA): UN BASTIÓN AGRÍCOLA. Revista Geográfica Digital. IGUNNE. Facultad de Humanidades. UNNE. Año 13. N N 26. Julio - Diciembre 2016. ISSN 1668-5180 Resistencia, Chaco.

En: http://hum.unne.edu.ar/revistas/geoweb/default.htm 
"La soja tuvo varias razones para instalarse en el Chaco, en realidad una zona marginal para la misma, entre ellas se pueden señalar la pérdida de posiciones del algodón como consecuencia de la caída internacional del precio; muchos productores del textil se pasaron a la soja como respuesta a sus virtudes". "La demanda interna así como la elevación de su precio, la facilidad de adaptación de las nuevas variedades especialmente las transgénicas, la existencia de tierras nuevas para comprar o arrendar a bajos precios, la facilidad del desmonte, un período vegetativo menor al algodón, menos labores culturales y fundamentalmente la presencia de agricultores de otras provincias...Estos productores, con recursos suficientes, se abocaron a la plantación de soja y su rotación con el trigo. Otra razón que extendió la frontera agropecuaria hacia el Oeste fue el aumento de las lluvias que corrió la isohieta de $800 \mathrm{~mm}$ unos 200 - 300 km hacia Santiago del Estero..." (Manoiloff, R., 2005)

Después de 2003 la soja se mantuvo como el cultivo más sembrado; no obstante, ha mostrado un comportamiento decreciente, al tiempo que el algodón -en la mayoría de las campañas- ha exhibido una tendencia progresiva, disputando el segundo lugar con el girasol. El maíz, el sorgo y el trigo representan valores de siembra inferiores en las últimas campañas.

Figura $N^{\circ} 4$ :

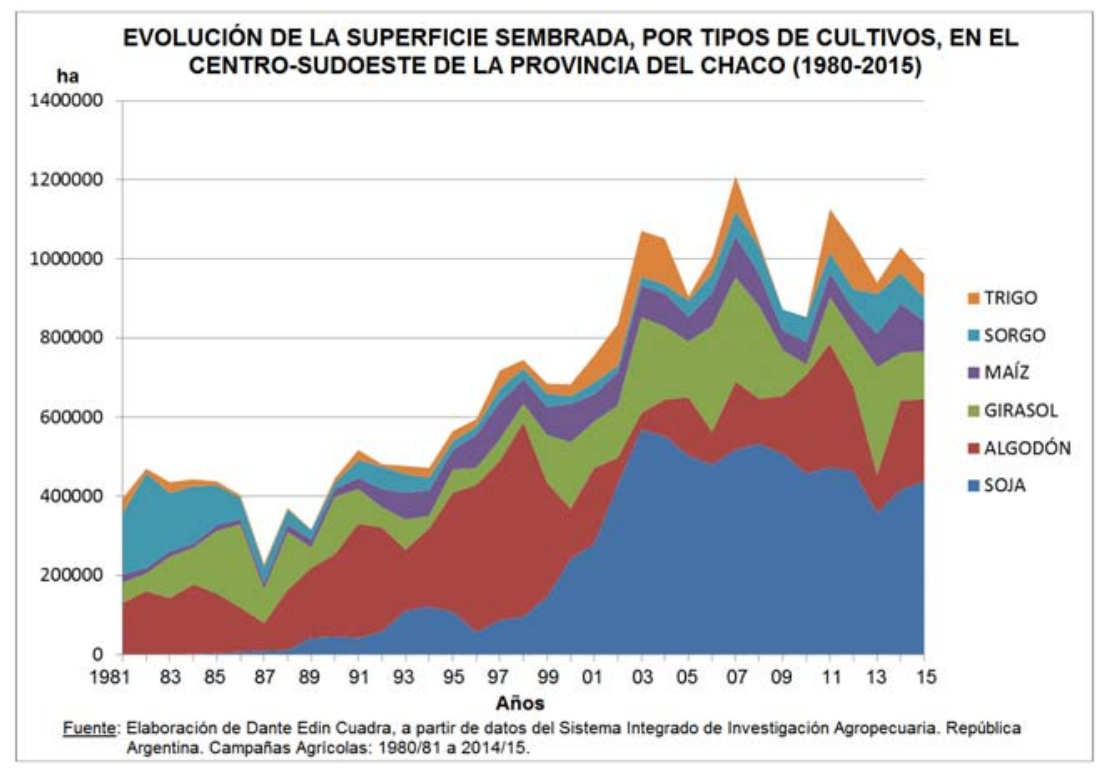

La participación relativa de los cultivos en la región Centro-Sudoeste nos permite advertir que, a principios de la década de 1980, la soja no estaba en los planes de ningún agricultor, apareciendo tenuemente a mediados de la misma; ya en 1989 representaba el $12 \%$ de la superficie sembrada y, en 1994 , la proporción ascendía a $25 \%$. El algodón era claramente el cultivo con más predilección en el área, muchas veces concentrando más de la mitad de la superficie de siembra.

Entre los años 1994 y 1999 se advierte un fuerte incremento de la plantación de algodón, que repercutió en un retraimiento del área sojera y de otros cultivos, pero tras ello se produjo el crecimiento explosivo de la implantación de soja, la cual alcanzó una amplitud de 50 a $60 \%$ del área cultivada durante gran parte de la primera década del siglo XXI, etapa en la que el girasol se posicionaba como el segundo cultivo de la región. En la campaña 2014/2015 la oleaginosa representó el $46 \%$ de la superficie sembrada, el algodón $21 \%$, el girasol $12 \%$, en tanto la sumatoria de maíz, sorgo y trigo conformaba el $21 \%$. 
Revista Geográfica Digital. IGUNNE. Facultad de Humanidades. UNNE. Año 13. № 26. Julio - Diciembre 2016. ISSN 1668-5180 Resistencia, Chaco

Figura $\mathbf{N}^{\circ}$ 5:

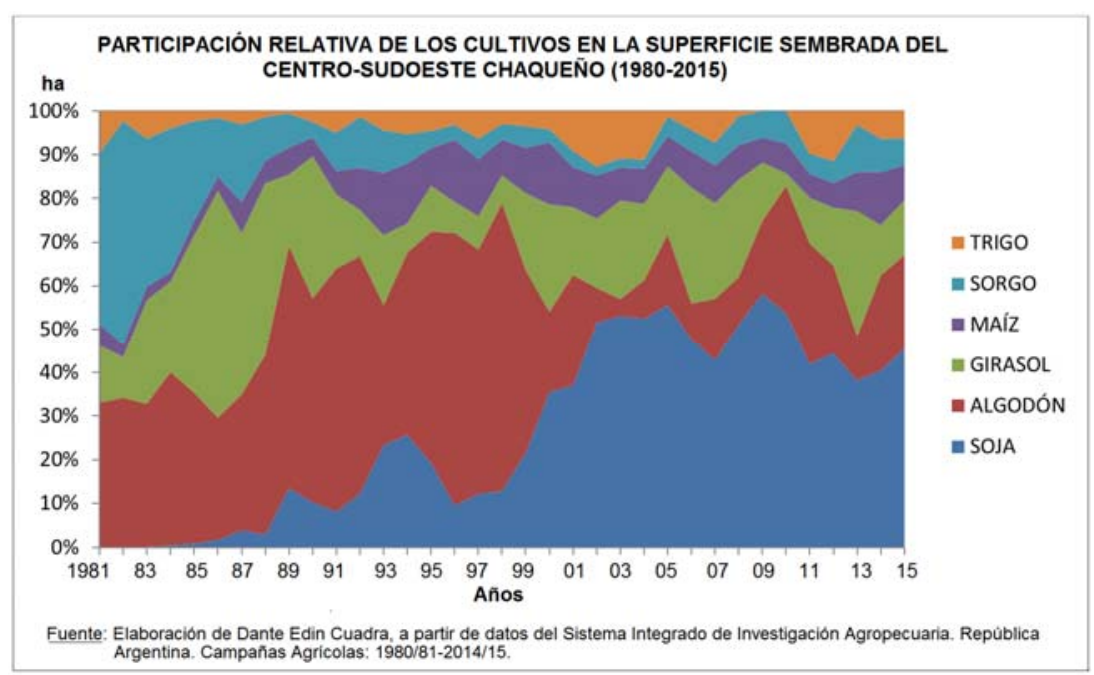

\section{La relación algodón-soja en el Centro-Sudoeste chaqueño}

Hasta la campaña agrícola 1998/99, la siembra de algodón mostraba un crecimiento sostenido en la región, acercándose al medio millón de hectáreas sembradas, en tanto, la soja registraba un crecimiento, pero con valores que apenas lograban superar las 100.000 hectáreas. Pero en las siguientes campañas (1999/00 a 2002/03) se asistió a una estrepitosa caída en la siembra del textil (hasta un piso inferior a 50.000 hectáreas) y, opuestamente, a un abrupto crecimiento de la superficie sojera (más de 550.000 hectáreas). En las campañas que prosiguieron la soja fue reduciendo levemente su área de siembra (cerca de 450.000 hectáreas en 2014/15) y el algodón fue recuperando parte del terreno perdido (200.000 hectáreas en esa misma campaña).

Figura $N^{\circ} 6$ :

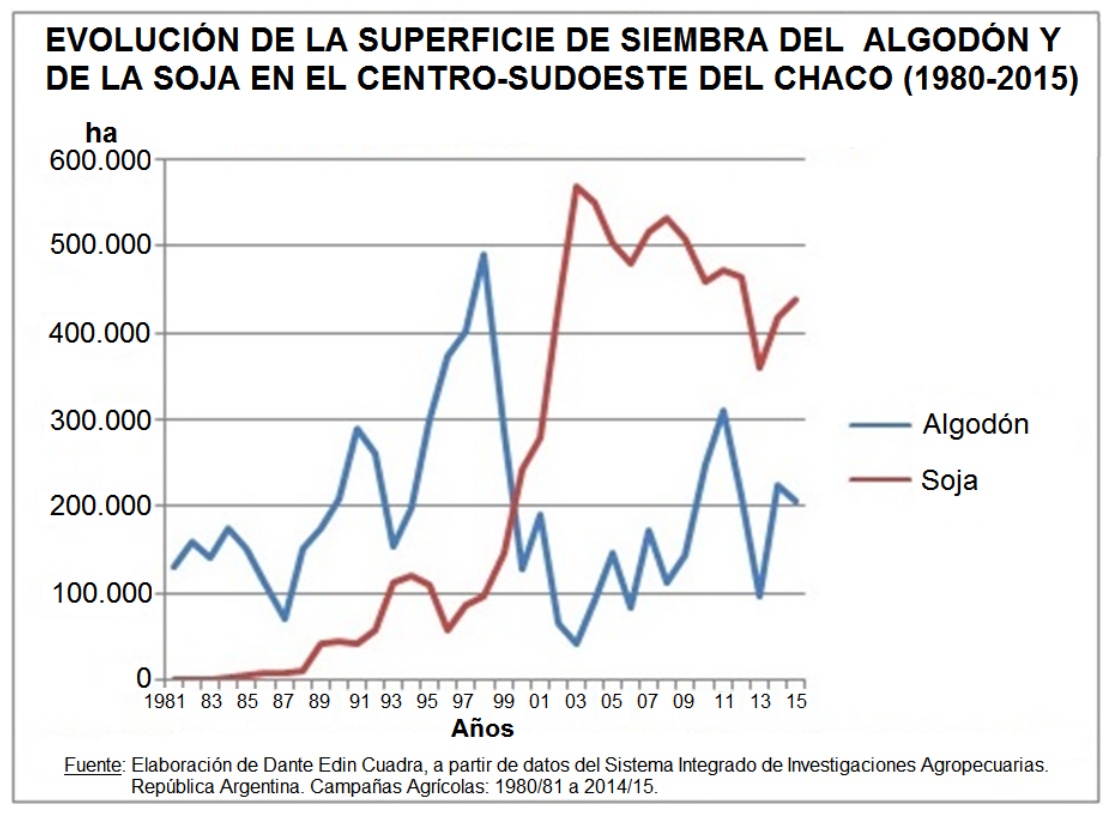

Publicado en formato digital: Dr. Dante Edin Cuadra y Sr. Nelson Adrián Mónaca. EL CENTRO-SUDOESTE DE LA PROVINCIA DEL CHACO (ARGENTINA): UN BASTIÓN AGRÍCOLA. Revista Geográfica Digital. IGUNNE. Facultad de Humanidades. UNNE. Año 13. N N 26. Julio - Diciembre 2016. ISSN 1668-5180 Resistencia, Chaco.

En: http://hum.unne.edu.ar/revistas/geoweb/default.htm 
Revista Geográfica Digital. IGUNNE. Facultad de Humanidades. UNNE. Año 13. № 26.

Julio - Diciembre 2016. ISSN 1668-5180 Resistencia, Chaco

\section{Cultivos por departamentos de la región Centro-Sudoeste}

\section{Algodón}

Las jurisdicciones administrativas con mayor participación en el cultivo de algodón, a lo largo del período, fueron Comandante Fernández, O’Higgins, Mayor Luis Fontana, 12 de Octubre y Fray Justo Santa María de Oro, ubicados en el Este y Sur de la región.

En 1980, entre las propuestas realizadas por el INTA para salir de la situación crítica en la que se hallaban los productores rurales, se encontraba la de "Acrecentar la superficie de las chacras por medio del desmonte de las tierras con aptitudes agrícolas, promover la fusión de las explotaciones agropecuarias, otorgar créditos especiales para favorecer el incremento del tamaño de las explotaciones, incorporar tecnología y la recombinación de los rubros". Además, dicha institución “...aconsejaba, en la medida de lo posible, la diversificación de las actividades agrícolas y ganaderas, como un reaseguro que permita ingresos de más de un origen al agricultor de manera que no quede desamparado si, por ejemplo, el algodón fracasara". (Manoiloff, R., 2001)

Buena parte de ese escenario futuro sugerido por el INTA se fue conformando en la década siguiente, cuando el algodón se sembró en áreas de mayor extensión resultantes de la anexión de predios y la incorporación de tierras de desmontes, haciéndose en forma mecanizada (sin braceros) y con incorporación tecnológica. Este proceso impulsó la concentración de la tierra (más hectáreas en manos de menos productores) y fue el trampolín que favoreció la inmediata arremetida sojera en esta parte del Chaco. En el Centro-Este del Chaco, donde las tierras agrícolas se hallaban más subdivididas (más propietarios con menores superficies) la dominancia de la soja no tuvo mucha duración.

El cultivo del algodón es altamente sensible a situaciones políticas y económicas adversas y, como puede apreciarse, la drástica reducción de la superficie de siembra del año 1987 estuvo vinculada a la crisis económica y a la alta inflación imperante (sumadas al bajo precio de la fibra en el mercado internacional), situación que volvió a desencadenarse en 2003 en el marco de una profunda crisis política y económica.

En el medio de esas crisis, se vivió lo que parecía la gran recuperación del algodón en la década de 1990, alcanzándose el record histórico de este cultivo (cerca de medio millón de hectáreas sembradas en esta región), destacándose Comandante Fernández, 12 de Octubre, O’Higgins y Mayor Fontana). Después de 2009 se registraron nuevas situaciones alentadoras, sobrepasándose las 200.000 hectáreas en varias campañas agrícolas. En las más recientes, las jurisdicciones que más han apostado al cultivo del textil han sido Mayor Fontana, O'Higgins y Fray Justo Santa María de Oro, situadas en el Este y Sur de la región.

"Desde los años 90, en el agro argentino se desarrolló un importante proceso de cambio tecnológico, impulsado inicialmente en la planicie chacopampeana. Esos cambios...generaron transformaciones en las formas de producción, en la apropiación de los recursos, en el uso de la tierra y de los recursos naturales. Cabe destacar también la escala creciente de la producción anual de los cultivos de exportación, la intensificación en el uso de insumos y los nuevos conocimientos de gestión agropecuaria, de manejo del capital económico y financiero, y de los recursos humanos". (Pengue, W., 2016)

Rápidamente el territorio Centro-Sudoccidental chaqueño se incorporó a este proceso y, si bien es cierto que algunos departamentos como 12 de Octubre, Chacabuco, Comandante Fernández, General Belgrano y 9 de Julio (cuyas cabeceras son General Pinedo, Charata, Presidencia Roque Sáenz Peña, Corzuela y Las Breñas, respectivamente) han logrado destacarse por la amplitud de tierras dedicadas a la siembra de soja, lo llamativo es que no se sacan grandes diferencias entre sí, lo que significa que este cultivo ha logrado una implantación generalizada en la región, que sólo mengua en extensión en aquéllas jurisdicciones en las que también se desarrolla la ganadería y la plantación de algodón, como sucede en Mayor Fontana y Fray Justo Santa María de Oro.

Publicado en formato digital: Dr. Dante Edin Cuadra y Sr. Nelson Adrián Mónaca. EL CENTRO-SUDOESTE DE LA PROVINCIA DEL CHACO (ARGENTINA): UN BASTIÓN AGRÍCOLA. Revista Geográfica Digital. IGUNNE. Facultad de Humanidades. UNNE. Año 13. N N 26. Julio - Diciembre 2016. ISSN 1668-5180 Resistencia, Chaco.

En: http://hum.unne.edu.ar/revistas/geoweb/default.htm 
Revista Geográfica Digital. IGUNNE. Facultad de Humanidades. UNNE. Año 13. № 26. Julio - Diciembre 2016. ISSN 1668-5180 Resistencia, Chaco

Figura $\mathbf{N}^{\circ}$ 7:

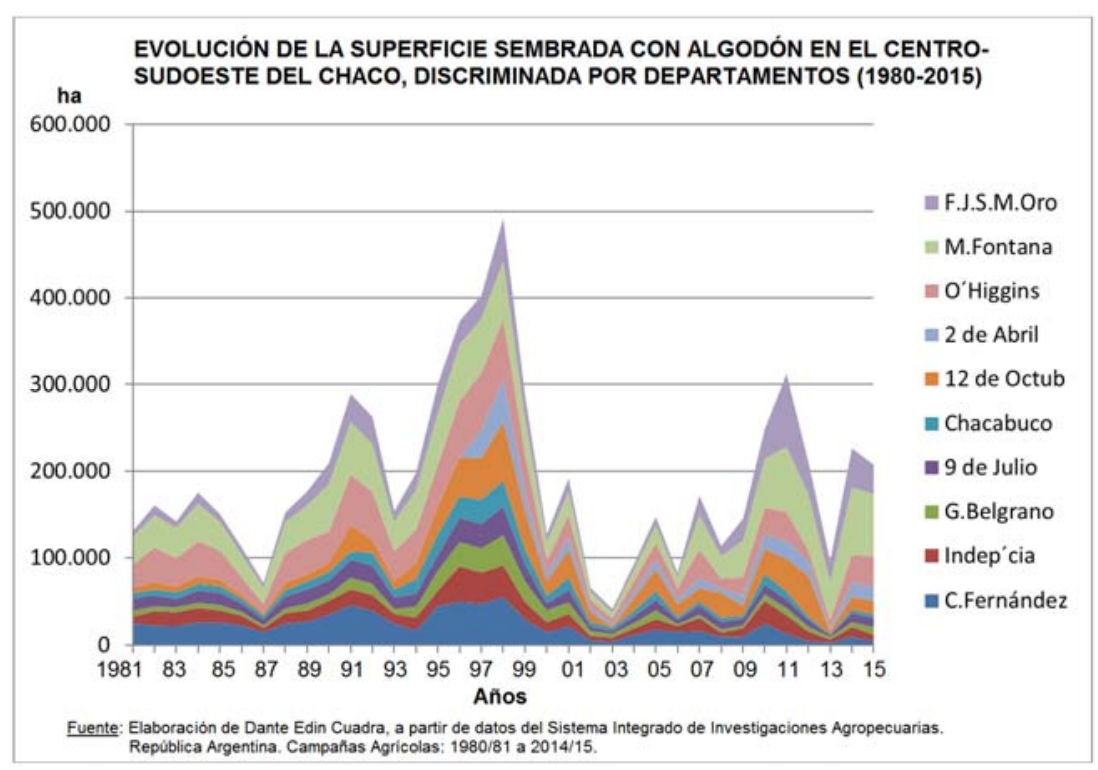

El precio internacional de la tonelada de soja, desde mediados de los '90 hasta el año 2006 osciló entre los 200 y 300 dólares, excepto el período 1999-2002 durante el cual estuvo levemente por debajo de los 200 dólares. De allí en más experimentó un alza muy significativa por encima y por debajo de los 400 dólares hasta 2010; en 2012 y 2013 llegó a traspasar los 500 dólares (precio record de 612,29 dólares en julio de 2012), para ubicarse por arriba de los 350 dólares en 2015 y 2016 . El gobierno argentino ha aplicado retenciones a la exportación de granos en los últimos años, que para la soja representó un $35 \%$ hasta 2015. En 2016 se quitó este mecanismo para los demás granos, pero no a la soja que continúa pagando un canon de $30 \%$, proporción que se iría reduciendo mensualmente en $0,5 \%$ a partir de 2018. Estas medidas políticas pueden cumplir el rol de reguladoras, potenciando la siembra de algunos cultivos y desalentando la de otros: por ejemplo, en la campaña 2015/16 se espera una reducción de la superficie sojera y un aumento del área sembrada con girasol, dado que este último goza de una mejor cotización al estar liberado de retenciones.

En el año 2003 se alcanzó el record de extensión sojera en la región Centro-Sudoeste del Chaco, superándose las 550.000 hectáreas. La tendencia posterior fue decreciente y en 2014/15 se situaba por debajo de las 450.000 hectáreas.

\section{Girasol}

El girasol es una planta perteneciente a la familia de las Compuestas o Asteráceas que se ha extendido en el Chaco, sobre todo después de la gran crisis algodonera desencadenada a finales de la década de 1950 y comienzos de los '60. Ha sido uno de los cultivos más difundidos durante la etapa de "pampeanización" del Chaco que se prolongó fuertemente, al menos, durante tres décadas. Podemos decir que, con excepción de la década de 1990 (lapso de resurgimiento del algodón), este proceso de "pampeanización" ha recobrado su vigencia hasta nuestros días, en virtud de que cinco de los seis cultivos predominantes en el Chaco se han instalado previamente en la región Pampeana. En los últimos años, el girasol disputa con el algodón el segundo lugar en la cobertura de siembra del Centro-Sudoeste chaqueño, después de la soja y, luego, se ubican el maíz, el sorgo y el trigo.

A lo largo del período considerado esta región nunca superó las 275.000 hectáreas sembradas con girasol, observándose una gran irregularidad entre campañas, donde entran a jugar diferentes factores a la hora de decidir qué sembrar: uno de ellos es el meteorológico, sino basta mirar la campaña 2009/2010 en la que la superficie implantada fue ínfima debido a la gran sequía que afectó al Chaco

Publicado en formato digital: Dr. Dante Edin Cuadra y Sr. Nelson Adrián Mónaca. EL CENTRO-SUDOESTE DE LA PROVINCIA DEL CHACO (ARGENTINA): UN BASTIÓN AGRÍCOLA. Revista Geográfica Digital. IGUNNE. Facultad de Humanidades. UNNE. Año 13. N N 26. Julio - Diciembre 2016. ISSN 1668-5180 Resistencia, Chaco.

En: http://hum.unne.edu.ar/revistas/geoweb/default.htm 
durante los meses de siembra de este cultivo. Otras veces pueden intervenir otras causales meteorológicas como la concentración o exceso de lluvias en períodos clave de siembra, germinación o crecimiento, incidencia de vientos desecantes del sector Norte durante la fase inicial de desarrollo de las plantas y, por otro lado, alternativas vinculadas con el mercado (precios alentadores del girasol o de otros cultivos sustitutos capaces de aportar mayores beneficios económicos al productor, nivel de expectativas de la demanda externa e interna y costos del transporte, entre otras) y con las políticas estatales (existencia o no de retenciones impositivas, de créditos y subsidios, de aranceles aduaneros para la importación de maquinarias, políticas de aliento y promoción de actividades económicas, etc.).

Figura No 9:

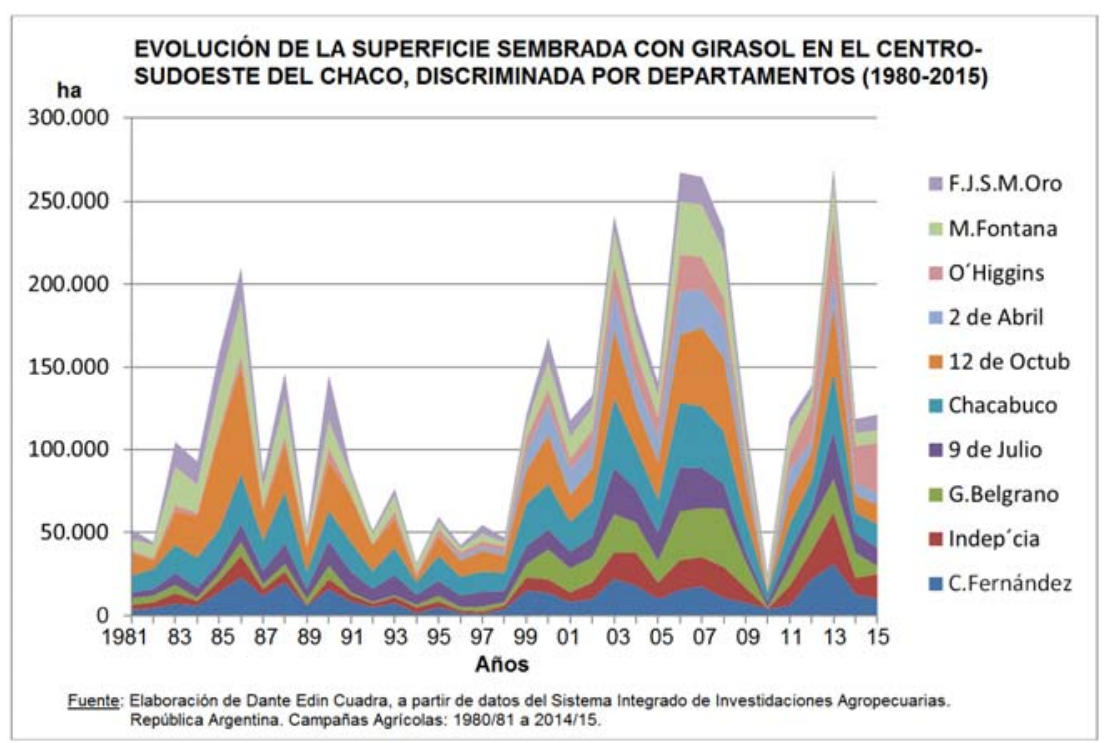

La década de 1990 fue la etapa en que menos girasol se sembró en esta región, debido al auge cobrado por el algodón. Sin embargo, los años '80 le fueron muy propicios, sobre todo desde la campaña 1998/99 en adelante, cuando casi siempre se mantuvo por arriba de las 100.000 hectáreas sembradas, llegando a superar las 250.000 hectáreas en algunos años.

Los departamentos que han tenido relevancia en la siembra de esta oleaginosa en la región CentroSudoeste del Chaco a lo largo del período fueron Comandante Fernández, Chacabuco, 12 de Octubre y Mayor Fontana (en la década de 1980), a los que se agregaron Independencia, General Belgrano, 9 de Julio, 2 de Abril y O'Higgins en el presente siglo. En la actualidad, el área de siembra está repartida con bastante equilibrio en toda la región, destacándose el departamento O'Higgins (colonias cercanas a las ciudades de San Bernardo, La Clotilde y La Tigra).

\section{Maíz}

Este cultivo, perteneciente a la familia de las Poáceas, ha estado presente en las chacras y huertas del Chaco desde fines del siglo XIX, en función de sus bondades tales como la buena adaptación al ambiente, provisión de alimento para humanos y animales, facilidad de cosecha, etc. Durante el período considerado se observa que durante la década de 1980 no ha tenido gran acogida en el Centro-Sudoeste chaqueño (por debajo de 20.000 hectáreas), pero de allí en adelante experimentó un despegue importante que se prolonga hasta la actualidad, superando las 60.000 hectáreas en la mayoría de las campañas e, incluso, en algunas de ellas las 100.000 hectáreas. Los departamentos que más se destacan son Chacabuco, 12 de Octubre, 9 de Julio, Independencia y Comandante Fernández. 
Revista Geográfica Digital. IGUNNE. Facultad de Humanidades. UNNE. Año 13. № 26. Julio - Diciembre 2016. ISSN 1668-5180 Resistencia, Chaco

Figura $\mathbf{N}^{\circ}$ 10:

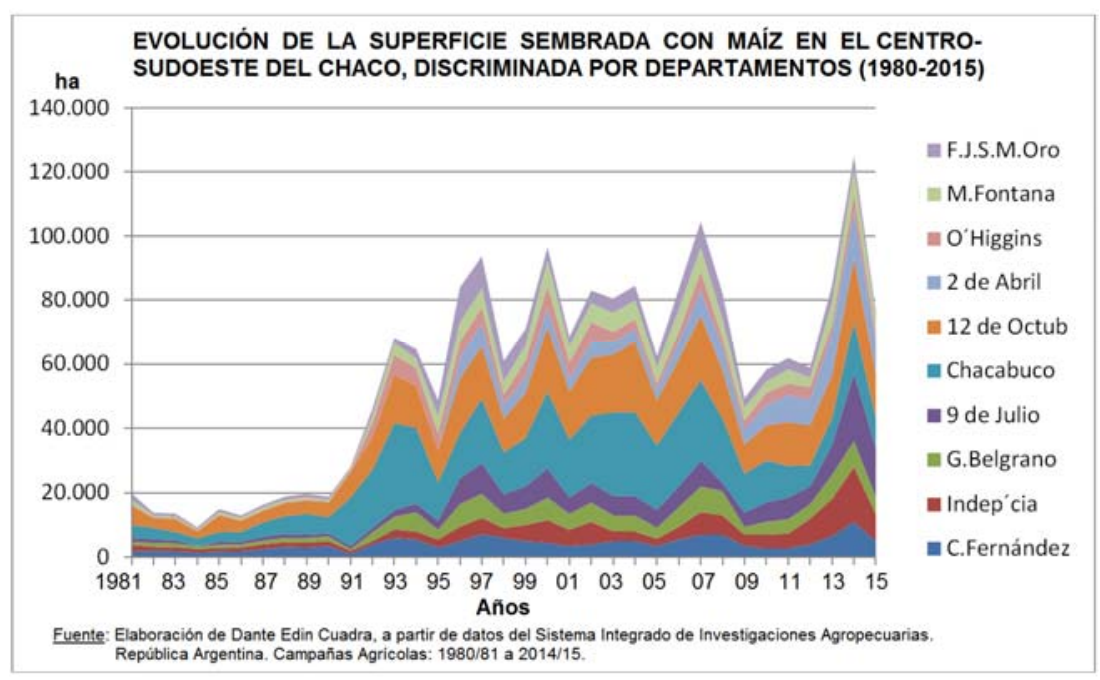

\section{Sorgo}

El sorgo es una planta Poácea (gramínea) de gran tolerancia al calor y a la sequía (forrajera de verano), cuyos granos se utilizan mayormente para el consumo animal en nuestro país, al igual que el resto de su biomasa aérea.

En la región Centro-Sudoeste del Chaco este cultivo tuvo difusión durante la primera mitad de la década de 1980, llegándose a superar las 200.000 hectáreas sembradas. Desde fines de los ' 80 hasta promediar la década de 2010 su implantación ha estado, con frecuencia, por debajo de las 50.000 hectáreas y, recién en los últimos años, logró colocarse por encima de ese valor. Puede considerárselo un cultivo marginal en esta área, en la cual los departamentos se distribuyen la superficie de siembra de una forma bastante proporcional, aunque si tomamos la totalidad del período 1980-2015 se evidencia que prevalecen 12 de Octubre, Chacabuco y Comandante Fernández.

Figura $\mathbf{N}^{\circ}$ 11:

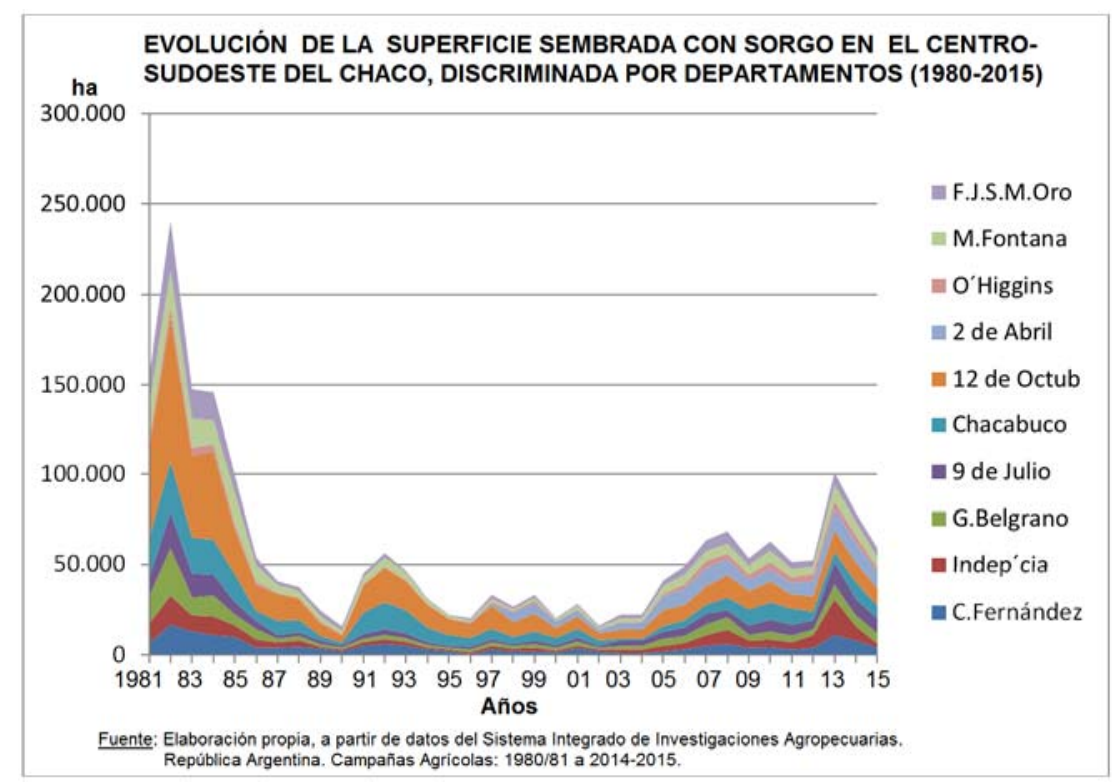

Publicado en formato digital: Dr. Dante Edin Cuadra y Sr. Nelson Adrián Mónaca. EL CENTRO-SUDOESTE DE LA PROVINCIA DEL CHACO (ARGENTINA): UN BASTIÓN AGRÍCOLA. Revista Geográfica Digital. IGUNNE. Facultad de Humanidades. UNNE. Año 13. N N 26. Julio - Diciembre 2016. ISSN 1668-5180 Resistencia, Chaco.

En: http://hum.unne.edu.ar/revistas/geoweb/default.htm 
Revista Geográfica Digital. IGUNNE. Facultad de Humanidades. UNNE. Año 13. № 26. Julio - Diciembre 2016. ISSN 1668-5180 Resistencia, Chaco

\section{Trigo}

Esta planta también es una Poácea (gramínea) que se cultiva en el Centro-Sudoeste del Chaco con bastante variación areal y de rendimientos entre las sucesivas campañas. El Chaco es un espacio geográfico marginal para este cultivo y, en razón de ello, los volúmenes de cosecha son muy inferiores con respecto a las áreas centrales del país. No obstante, los agricultores suelen incorporarlo en su esquema productivo por tratarse de un cultivo de invierno que permite mantener el suelo con buena estructuración y humedad a lo largo de una época caracterizada por la insuficiencia de las precipitaciones, al tiempo que le aporta materia orgánica y evita el avance de plagas en tierras de laboreo que, luego de esta cosecha fina, admiten la siembra de otro cultivo, por ejemplo girasol, algodón o soja.

En función de las contingencias meteorológicas y de otros factores políticos y de mercado que pudieran presentarse, la siembra muestra una alta irregularidad areal entre campañas (de 0 a 120.000 hectáreas). Puede advertirse que en la campaña 2009/10 no se ha sembrado trigo en esta región, resultado de la acuciante sequía que, a lo largo de ocho meses, abatió al territorio chaqueño.

Se advierte que durante las décadas de 1980 y 1990 no fue un cultivo de relevancia en la región (rara vez superó las 30.000 hectáreas), pero en los años transcurridos del presente siglo ha tomado una envergadura mayor, con excepción de los años muy secos, justamente por el esquema de producción incorporado que requiere suelos no compactados, presencia de materia orgánica y humedad a la hora de sembrar cultivos de mayor rentabilidad para el productor (soja, girasol o algodón).

Entre las jurisdicciones que más se destacan en la siembra de este cereal se hallan 12 de Octubre, Chacabuco, 9 de Julio, O’Higgins, Independencia, General Belgrano y Comandante Fernández.

Figura $\mathbf{N}^{\circ} 12$

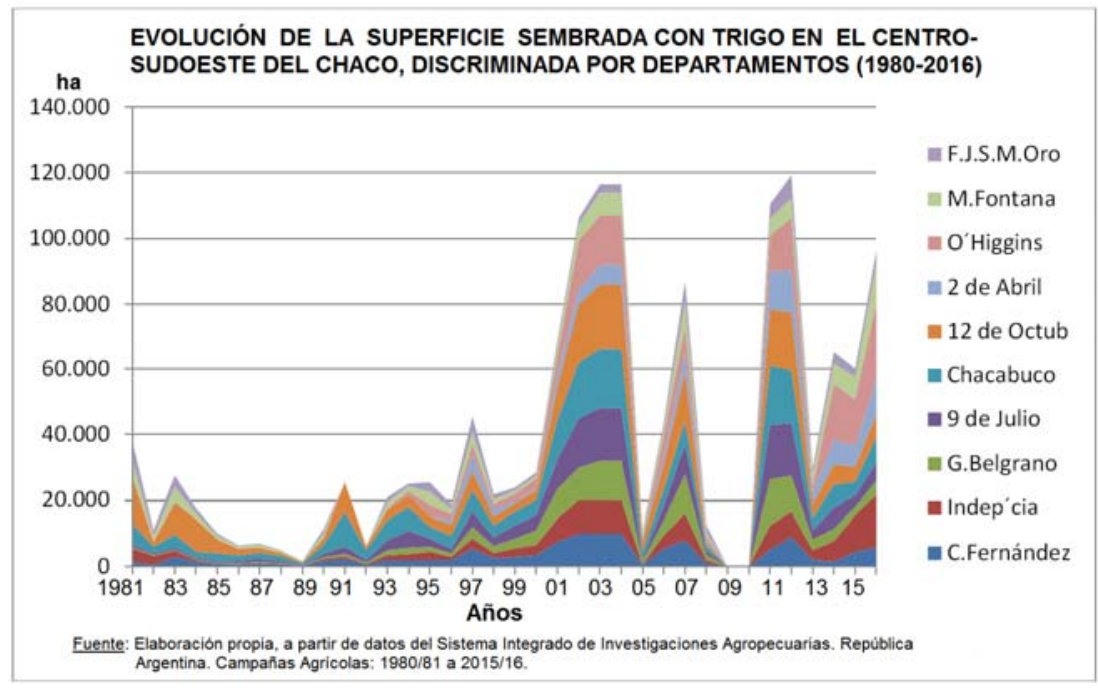

Publicado en formato digital: Dr. Dante Edin Cuadra y Sr. Nelson Adrián Mónaca. EL CENTRO-SUDOESTE DE LA PROVINCIA DEL CHACO (ARGENTINA): UN BASTIÓN AGRÍCOLA. Revista Geográfica Digital. IGUNNE. Facultad de Humanidades. UNNE. Año 13. № 26. Julio - Diciembre 2016. ISSN 1668-5180 Resistencia, Chaco.

En: http://hum.unne.edu.ar/revistas/geoweb/default.htm 
Imágenes de algunos cultivos de la región Centro-Sudoeste del Chaco

Soja

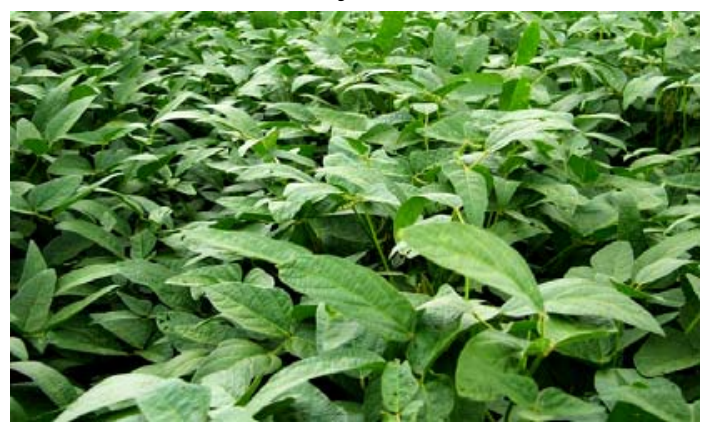

Sorgo

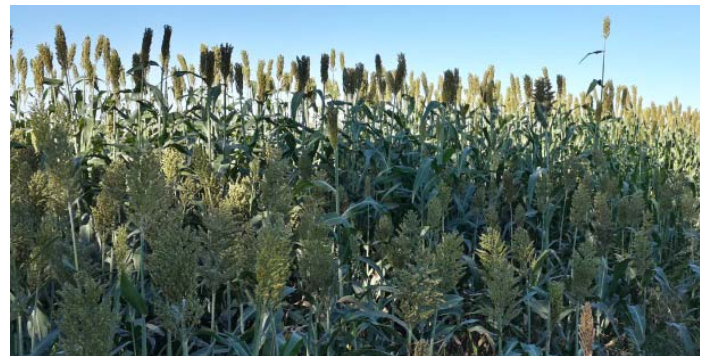

Girasol

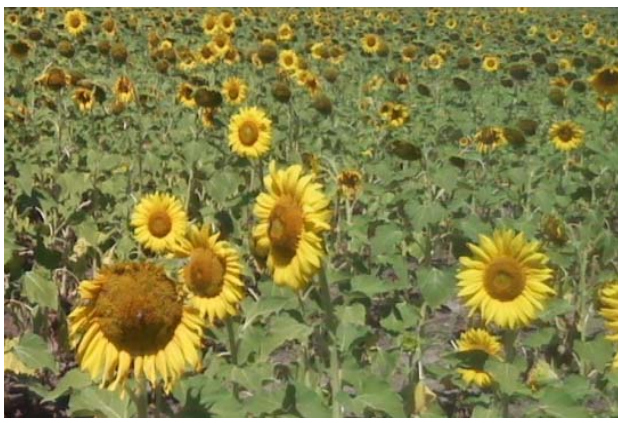

Maíz

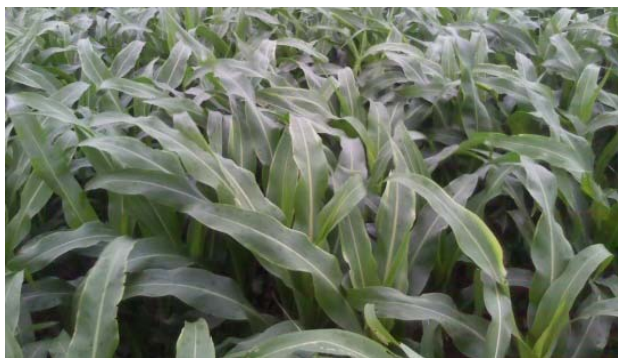

\section{Conclusiones}

La región productiva del Centro-Sudoeste chaqueño, en las últimas décadas y particularmente en el tramo hasta aquí recorrido del siglo XXI, ha logrado consolidarse como el área núcleo de la actividad agrícola de la provincia.

Este espacio fue escenario de importantes cuencas algodoneras entre 1930 y 1960; luego, entre este último año y 1990, logró expandir la siembra de cultivos tradicionalmente implantados en la región Pampeana (sobre todo girasol y sorgo), sin abandonar la labranza del algodón. En la década del '90 concentró potentemente el cultivo del textil incorporando la mecanización y, ya en la transición de los siglos XX y XXI, se constituyó en el área de mayor producción sojera de la provincia.

Rápidamente se concretó una profunda transformación de la fisonomía y del paisaje agrario de esta región, impulsada por la irrupción de una nueva matriz productiva y el consiguiente arribo de paquetes tecnológicos, de nuevas modalidades empresariales, la llegada de productores y arrendatarios de otras provincias y, necesariamente, la adaptación de los agricultores locales (con capacidad de inversión suficiente) a las nuevas reglas de juego. Fueron varios los factores que se alinearon para que este proceso se desencadenara sin grandes perturbaciones, entre ellos: la disponibilidad de tierras en venta y en arriendo a menores costos en comparación con el centro del país, los escasos frenos a la deforestación, la caída abrupta de la producción algodonera a fines de la década de 1990, la existencia de una práctica de mecanización agrícola aplicada años anteriores al cultivo del algodón, los atractivos precios internacionales del commodity sojero y la fuerte demanda de granos por parte de China.

Son muchas las ciudades que se han visto dinamizadas por los cambios operados en la región (Charata, Las Breñas, Presidencia Roque Sáenz Peña, Villa Ángela y General Pinedo son algunas de ellas), que se evidencian a través de inversiones inmobiliarias, construcciones edilicias, venta de 
vehículos, de maquinarias e insumos agrícolas, instalación de acopiadores, incremento de actividades transportistas, financieras y bancarias, demanda de personal técnico y profesional, etc.

Por cierto, en el Centro-Sudoccidental del Chaco se emplaza actualmente $3 / 4$ partes de la superficie agrícola total de la provincia, situación que no es un dato menor pensando en una adecuada planificación territorial en el marco de políticas públicas que contemplen un desarrollo genuino e integral de este espacio geográfico. Tal finalidad no sería posible sin la potenciación y vinculación de los sectores públicos y privados, la incorporación de infraestructura vial, hidráulica, sanitaria y educativa y, asimismo, la mejora en cantidad y calidad de la cobertura de servicios a la población rural, urbana y periurbana.

Detrás del boom agrícola analizado, subyacen y emergen muchas dudas sobre las bondades de los productos transgénicos, los efectos reales del glifosato y de otros agroquímicos sobre la salud humana, animal y ambiental. Asimismo, es innegable la pérdida de población rural que sufrió esta región, tanto de pequeños productores como de peones, con picos en la década de 1990. En tal sentido, una gobernanza adecuada (legítima) debe preocuparse por la ciudadanía, garantizando la sustentabilidad de las actividades económicas que se llevan a cabo en el territorio, el monitoreo constante de la salud de sus habitantes, la utilización de indicadores ambientales de contaminación (en aguas, suelos, aire y organismos vegetales, animales y humanos), el control exhaustivo del manejo de agro-tóxicos y la implementación de campañas de concienciación en los distintos estamentos del tejido social. Si la transformación de un territorio no se encamina hacia el desarrollo, el cual incluye ineludiblemente la elevación de la calidad de vida de todas las personas que lo habitan, estaríamos -una vez más- ante un ciclo económico que tarde o temprano pasará y, tras él, quedarán gratitudes para unos y, desgraciadamente, despojos y miserias para otros. 


\section{Bibliografía y materiales consultados}

BESIL, Antonio C. (1969): Análisis de las causas del actual cambio en la estructura del sector agrícola de la provincia del Chaco. Tesis Doctoral. Facultad de Ciencias Económicas, UNNE. Resistencia, Argentina.

BISANG, Roberto; ANLLÓ, Guillermo y CAMPI, Mercedes (2009): Una revolución (no tan) silenciosa. Claves para repensar el agro en Argentina. CEPAL. Buenos Aires, Argentina.

BRUNIARD, Enrique D. (1979): El Gran Chaco Argentino. Revista Geográfica No 4. Instituto de Geografía. UNNE. Resistencia, Argentina.

CUADRA, Dante E. (2015): Cambios en las actividades agropecuarias y forestales en la provincia del Chaco (Argentina) y sus efectos sobre la población rural. En: Revista Geográfica Digital. Instituto de Geografía (IGUNNE) Facultad de Humanidades. UNNE. Año 12. № 23. Enero Julio. ISSN 1668-5180. Resistencia, Argentina. http://hum.unne.edu.ar/revistas/geoweb/homeig0.htm

MANOILOFF, Raúl O. (2001): El cultivo del algodón en el Chaco entre 1950 y nuestros días: la etapa de crisis. Meana Editores. Resistencia, Argentina.

MANOILOFF, Raúl O. (2005): La crisis del algodón en el Chaco y los cultivos alternativos. Corrientes, Argentina: Moglia S.R.L.

PENGUE, Walter A. (2016): Comida no...biomasa. Cambios agronómicos, ambientales y económicos en la agricultura argentina y sudamericana. En: Revista Nueva Sociedad. № 262. Marzo-Abril. Buenos Aires, Argentina.

PERTILE, Viviana C. (2004): Ampliación de la Frontera Agropecuaria Chaqueña: El Oeste chaqueño y el cultivo algodonero. En: Revista Geográfica Digital. Instituto de Geografía (IGUNNE) Facultad de Humanidades. UNNE. Año 1. No 1. Marzo - Abril. ISSN 1668-5180. Resistencia, Argentina. http://hum.unne.edu.ar/revistas/geoweb/homeig0.htm

SIIA. Sistema Integrado de Investigaciones Agropecuarias. Ministerio de Agroindustrias. Presidencia de la Nación: Estadísticas Agrícolas. Campañas 1980/81 - 2015-16. Buenos Aires, Argentina. En línea: http://www.siia.gov.ar/sst_pcias/estima/estima_1.php

SVAMPA, Maristella (2013): El consenso de los Commodities y lenguajes de valoración en América Latina. En: Revista Nueva Sociedad. № 244. Marzo-Abril. Buenos Aires, Argentina.

VALEIRO, Alejandro (1998): El Nuevo Algodón ¿Son sustentables los cambios recientes del sector algodonero Argentino?. INTA. Santiago del Estero, Argentina. 